\title{
SIDS: EPIDEMIOLOGY, INFANT PHYSIOLOGY AND SALIVA ASPIRATION
}

\author{
Sigitas Chmieliauskas ${ }^{1,2}$, Sigitas Laima ${ }^{1,2}$, Karolina Ginčiene் $\dot{e}^{1,2}$, Gerda \\ Andriuškevičiūtė ${ }^{2}$ Meda Sutkevičiūtė ${ }^{1}$, Monika Stančiukaitė ${ }^{1}$, Jurgita Stasiūnienè $\dot{1}^{1}$, \\ Algimantas Jasulaitis ${ }^{1}$
}

\begin{abstract}
A sudden infant death syndrome (SIDS) is diagnosed in the case of a sudden and unexpected death of an infant during sleep and where an autopsy shows no obvious pathological lesions or injuries. Although literature indicates a wide range of risk factors, there is no single opinion on the specific cause of SIDS. This paper describes a study of 191 infant deaths in which the State Forensic Medicine Service established 29 SIDS cases. Microscopical and histological results of samples taken from sections of the respiratory system reveal serous fluid in the alveoli and change specific to asphyxia in all autopsy cases of infants diagnosed with SIDS. The risk of SIDS is highest in infants aged 1-4 months. Salivary gland secretion increases with the development of infant physiology, and this increase coincides with infant teething. However, in this phase, an infant's swallowing reflex is still to form completely. Findings suggest that the serous fluid found in the alveoli was from the salivary glands, and thus, saliva aspiration may be associated with infant deaths due to SIDS.
\end{abstract}

UDC Classification: 616-008; DOI: http://dx.doi.org/10.12955/cbup.v5.1050

Keywords: SIDS, salivation, asphyxia, sudden death

\section{Introduction}

Sudden infant death syndrome (SIDS) is a postmortem diagnosis for an infant, usually less than a year old, who dies suddenly and unexpectedly of natural causes during sleep with the reason indeterminable by an autopsy (Gilbert-Barness \& Debich-Spicer, 2005). In the USA, the incidence of SIDS reaches 1.2 birth cases, but overall, it ranges from 0.046 to 6.7 cases per 1000 births (Sharma, 2007). About 90-95\% of SIDS deaths occur in infants under six months of age, but according to different sources, the highest mortality peak is between 1-4 months (Janette \& Marshall Haith, 2009; Moon, Darnall, Goodstein, \& Hauck, 2011). In most cases, death occurs between midnight and 9 am. (Gilbert-Barness \& Debich-Spicer, 2005). Epidemiological studies have shown that SIDS cases increase during the winter months and they occur in male infants more often. According to the statistics, SIDS befalls more frequently on infants of a lower socioeconomic status, with young and unmarried women of poorer education, and on infants whose mothers took drugs before and during pregnancy. The risk of SIDS increases with prone sleeping position, bed sharing, hyperthermia, and hypothermia (Sharma, 2007).

\section{Data and Methodology}

In the period of 1995-2015, the State Forensic Medicine Service (SFMS) studied cases of deaths among children under 2-years old. The sample number was 191 with $15 \%(\mathrm{n}=29)$ diagnosed with sudden infant death syndrome, acute respiratory and cardiac disorder, and unspecified acute cardiac disorder. The Shapiro-Wilk normality test was used based on the data distribution according to the normality law. A 95\% confidence interval and a significance level ( $p$-values) of 0.05 were chosen.

Samples to determine levels of ethyl alcohol were collected from all infants and for drugs, psychotropic agents, and other highly active substances from 59\% of infants.

Infant sleeping positions were examined to identify the various SIDS risk factors and prevention models.

\section{Results and Discussion}

In the studied cases, $14 \%(\mathrm{n}=27)$ of the reported deaths due to SIDS occurred in hospital (Figure 1) with the majority $83 \%(\mathrm{n}=158)$ occurring at home (Figure 1$)$. Overall, $52 \%$ of the studied SIDS cases were male infants, and $48 \%$ were female (Figure 2).

The youngest infant diagnosed with sudden infant death syndrome was a 1-day old child and the oldest 2-years old. The median age was two months, with the mean $3.9 \pm 5.7$ months ( $p<0.005$; Figure 3 ).

\footnotetext{
${ }^{1}$ Faculty of Medicine, Vilnius University Lithuania.

${ }^{2}$ State Forensic Medicine Service, Vilnius, Lithuania.

E-mails: sigitas.chmieliauskas@mf.vu.lt, sigitaslaima@gmail.com, karolina.ginciene@gmail.com, andrgerda@yahoo.com, meda.sut@gmail.com, monika.stanciukaite@gmail.com,jurgita.stasiuniene@yahoo.com, algimantas.jasulaitis@mf.vu.lt
} 
The tests to determine the level of ethyl alcohol and other substances in samples showed negative results in all cases. The autopsies revealed traces of a foamy, pink liquid at the bifurcation of the trachea. Histological examination showed a mucous secretion present at places in the larger bronchi with eosinophilic masses (in parts with a yellowish-brown color) and extra mucus and desquamated bronchial epithelial cells in bronchial lumens. The lungs were of average elasticity, full-blooded, swollen, with uneven tissue airiness and focal swelling of hyaline membranes in several alveoli. Other findings included a bronchial epithelial desquamation in the lumen at places, serous fluid with little erythrocyte addition in the alveoli, and minor focal intra-alveoli swelling. Such an image dominates among cases of SIDS. A similar representation was observed in the infants who had died from asphyxia due to blockage of the airways (nose and mouth) and compression around the neck.

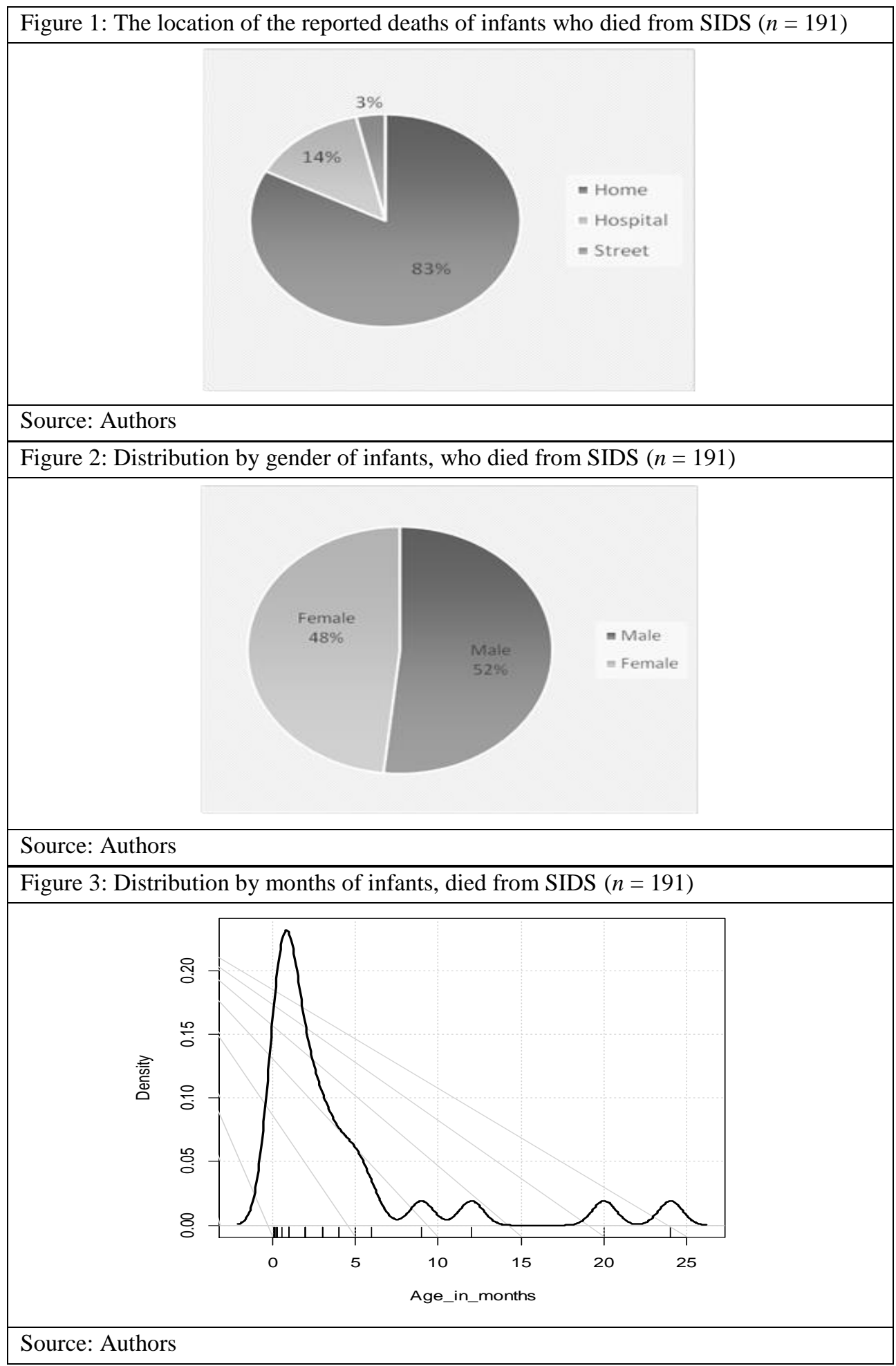




\section{The Postmortem Examination}

Although this topic is widely analyzed in the literature, and great deals of potential risk factors are provided, the findings of this study were inconclusive in determining the cause of SIDS. However, based on the literature data and the findings of the micromorphological and macromorphological examinations carried out by the State Forensic Medicine Service on respiratory system samples taken from the study cases, the cause of SIDS may relate to saliva aspiration. Especially, the excretion of saliva starts at about six weeks and increases with teething, coinciding with the age observed for most of the infant deaths attributed to SIDS, i.e., one to four months (Figure 3).

Infant Teething and Salivation

Infant teething starts around the age of 3-4 months (Castiglia, 1992; American Academy of Pediatrics, 2013). The study of Memarpour, Soltanimehr, and Eskandaria (2015) analyzed the most common symptoms that occur at the beginning of teething. The study, which included 254 children, found that the most common symptoms include salivation (92\%), sleeping disorders $(82.3 \%)$, and irritability (75.6\%; Memarpour, Soltanimehr, \& Eskandarian, 2015). During the first months, infant salivary glands secrete a small amount of saliva. Salivary gland secretion begins to increase from about six weeks (Nicory, 1922). There are three major pairs of salivary glands (parotid, submaxillary, and sublingual salivary glands) and about 700-1000 small salivary glands, which are located in the oral cavity and pharynx. All salivary glands begin to develop between 6-10 weeks of embryogenesis. The amount of all glandular secretion is about $0.3-0.5 \mathrm{ml} \mathrm{min}^{-1}$, and at maximum stimulation, this quantity can reach $1.5 \mathrm{ml} \mathrm{min}^{-1}$ (Heinrich \& Johannes, 2014). Parotid salivary gland secretion accounts for 20 $25 \%$ of the total saliva amount; submaxillary salivary glands, 65-70\%; and sublingual and small salivary gland secretion, 5\% each (Ekberg, 2012; Leung \& Pion Kao, 1999).

Examination of salivary gland excretion has revealed that higher excretion occurs in the afternoon than in the morning (Ekberg, 2012). In addition, Ekberg (2012) observed more saliva being released in winter than in the summer. Salivation can occur not only because of salivary hypersecretion, swallowing disorders, but also because of teething, central nervous system disorders, mental retardation, gastroesophageal reflux, drugs administered, and congenital genetic diseases. Small salivation is a relatively frequent phenomenon for infants and is considered normal until 18-24 months (Lakraj, Narges, \& Bahman, 2013). As infants' mouths are often open, their front teeth not yet fully grown, and a well-balanced swallowing reflex yet to form a little later, an elevated salivation in infants is common and is particularly striking in 5- to 6-month-old children (Leung \& Pion Kao, 1999). Only 18- to 24-month-old children learn to swallow with lip closure (Arvedson, 2006).

Swallowing

Despite the swallowing reflex forming in the fetus during the fourth month of prenatal development, the central nervous system does not develop until after birth, with mutual relations of the cortex and lower centers developing until the child is about one-year old (Rodier, 1994). The cortex begins to dominate in the central nervous system at about the fourth month of life when the conditional reflexes begin to form. One such reflex is mature swallowing (Campbell, 1971), which consists of a conscious oral-preparatory phase, i.e., conscious oral, pharyngeal, and esophageal phases. Infant swallowing does not involve conscious oral or oral-preparatory phases, and thus, infant swallowing of liquids differs from adult swallowing (Stevenson \& Allaire, 1991). This development of conditional reflexes protects an infant from choking and aspiration on saliva. During the period when an infant's liquid swallowing reflex is not sufficiently formed and salivary excretion is elevated, the risk of SIDS is the greatest.

\section{Infant Aspiration and Laryngospasm}

While an infant is sleeping, the non-swallowed saliva accumulates in the mouth which it can potentially leak into the respiratory tract and cause choking, aspiration, and laryngospasm. Dysphagia is a common cause of infant aspiration. Aspiration can be caused by stomach content regurgitation, a foreign body, or saliva entering the respiratory tracts. The aspiration of a large amount of substance into the lungs (macroaspiration) can cause a mechanical obstruction or aspirational pneumonitis, which provokes a severe hypoxia. Microaspiration irritates the upper respiratory tract and can trigger a reflex action that induces laryngospasm or bronchospasm (Mohan, 2002). Infants are characterized by an autonomic imbalance and increased parasympathetic activity in the larynx. Therefore, 
laryngospasm is more common among infants than adults (Campbell, 1971). Glottis closure is a protective respiratory tract reflex which occurs after contraction of internal laryngeal muscles to avoid aspiration (Ikari \& Sasaki, 1980; Gavel \& Walker, 2014). In the case of increased salivation, a sleeping infant with a partly formed swallowing reflex will have saliva entering the respiratory tract. The irritation of the vagus nerve receptors located around larynx could trigger a reflex action where the inner laryngeal muscles would contract and initiate laryngospasm causing asphyxia.

Infant Sleeping Positions

Various authors unanimously agree that the risk of SIDS is highest when an infant is placed in bed in a prone position (Moon \& Fu, 2012; Scragg \& Mitchell, 1998; Oyen, N., Markestad, T., Skaerven, R., Irgens, L. M., Helweg-Larsen, K., Alm, B. B., et al., 1997). Research suggests that sleeping in a prone position causes the autonomic cardiovascular system control to change, especially in infants of twothree months of age, and limit brain oxygenation (Moon \& Fu, 2012). Lying in the prone position causes the respiratory tract to compress; making it difficult to breathe and apnea develops (Scragg \& Mitchell, 1998). In 1999, the study examined laryngeal chemoreflex, which is a protective respiratory tract reflex. The study revealed that during sleep an infant lying in the prone position breathes and swallows less frequently than when lying on the back (Jeffery, Megevand, \& Page, 1999). In addition, after salivation increases saliva enters the nostrils of an infant lying in the prone position, which triggers a diving reflex that induces apnea, bradycardia, and arrhythmias (Campbell, 1971). Given these reasons, infants should not be laid in the prone position, but whether sleeping on the back or the side is safer remains unknown. Many authors argue that a child placed in the side position can easily to turn to the prone position (Scragg \& Mitchell, 1998) and believe that the position of laying on the back has the lowest risk for developing SIDS. Despite the position of sleeping on the side not being as safe as sleeping on the back, the risk of SIDS is deemed significantly lower in this position than in the prone position. Also, where an infant is laid on the side, caregivers should ensure that the child's hand is stretched out in a forward position to reduce the probability of an infant rolling into the prone position (American Academy of Pediatrics, 2005).

\section{Conclusion}

Information in the literature and results of microscopical and histological respiratory system investigations of infants who died of sudden infant death syndrome indicate traces of serous fluid found in the lungs of the study cases to be salivary gland secretion, i.e., saliva, which has entered the lungs during the infant's sleep. Possibly, incomplete development of the swallowing reflex and increased salivation contributes to sudden death by asphyxia. However, accepting this theory requires additional research. For example, in the case of a sudden infant death of a sleeping baby, a histological examination of the respiratory system during autopsy is recommended. After detection of serous fluid, a saliva S-amylase qualitative analysis (S-AMYL) would confirm whether this fluid is a salivary gland secretion, which could lead to an infant's asphyxia.

\section{References:}

American Academy of Pediatrics. (2005). The changing concept of sudden infant death syndrome: diagnostic coding shifts, controversies regarding the sleeping environment, and new variables to consider in reducing risk (Vol. 116).

American Academy of Pediatrics. (2013). A pediatric guide to children's oral health.

Arvedson, J. C. (2006, May 16). Swallowing and feeding in infants and young children. Retrieved from GI Motility online.

Campbell, K. (1971). Possible role of saliva in the sudden infant-death syndrome. Lancet, 2(7737), 1314-1315.

Castiglia, P. (1992). Teething. Journal of Pediatric Health Care, 6(3), 153-154.

Ekberg, O. (2012). Dysphagia. Diagnosis and Treatment.

Gavel, G., \& Walker, R. (2014). Laryngospasm in anaesthesia. Contin Educ Anaesth Crit Care Pain, 14(2), 47-51.

Gilbert-Barness, E., \& Debich-Spicer, D. (2005). Handbook of pediatric autopsy pathology.

Heinrich, I., \& Johannes, Z. (2014). Salivary gland diseases in children. GMS Curr Top Otorhinolaryngol Head Neck Surg, 13, Doc06.

Ikari, T., \& Sasaki, C. T. (1980). Laryngospasm: a neurophysiological definition. Ann Otol Rhinol Laryngol, 89, 220-224.

Janette, B., \& Marshall Haith, B. (2009). Diseases and disorders in infancy and early childhood (1 ed.).

Jeffery, H. E., Megevand, A., \& Page, H. (1999). Why the prone position is a risk factor for sudden infant death syndrome. Pediatrics, 104(2 Pt 1), 263-269.

Lakraj, A. A., Narges, M., \& Bahman, J. (2013). Sialorrhea: anatomy, pathophysiology and treatment with emphasis on the role of botulinum toxins. Toxins, 5, 1010-1031. 
Leung, A., \& Pion Kao, C. (1999). Drooling in children. Pediatr Child Health, 4(6), 406-411.

Memarpour, M., Soltanimehr, E., \& Eskandarian, T. (2015). Signs and symptoms associated with primary tooth eruption: a clinical trial of nonphar-macological remedies. BMC Oral Health, 15, 88.

Mohan, P. (2002). Aspiration in infants and children. Pediatrics in review, 23(9), 330-331.

Moon, R. Y., \& Fu, L. (2012). Sudden infant death syndrome: an update. Pediatr Rev, 33(7), 314-320.

Moon, R. Y., Darnall, R. A., Goodstein, M. H., \& Hauck, F. R. (2011). SIDS and other sleep-related infant deaths: expansion of recommendations for a safe infant sleeping environment. Pediatrics, 128(5), 1341-67.

Nicory, C. (1922). Salivary Secretion in Infants. Biochem J, 16(3), 387-389.

Oyen, N., Markestad, T., Skaerven, R., Irgens, L. M., Helweg-Larsen, K., Alm, B. B., et al. (1997). Combined effects of sleeping position and prenatal risk factors in sudden infant death syndrome: the Nordic Epidemiological SIDS Study. Pediatrics, 100 (4), 613-621.

Rodier, P. (1994). Vulnerable periods and processes during central nervous system development. Environ Health Perspect, 102(2), 121-124.

Scragg, R. K., \& Mitchell, E. A. (1998). Side sleeping position and bed sharing in the sudden infant death syndrome. Ann Med, 30(4), 345-349.

Sharma, B. R. (2007). Sudden infant death syndrome: a subject of medicolegal research. Am J Forensic Med Pathol, 28(1), 69-72.

Stevenson, R. D., \& Allaire, J. H. (1991). The development of normal feeding and swallowing. Pediatr Clin North Am, 38(6), 1439-1453. 